\title{
Rational construction of cross-linked porous nickel arrays for efficient oxygen evolution reaction
}

\author{
Kaili Zhang a, Shengjue Deng a, Yu Zhong a, Yadong Wang b, Jianbo Wu c, Xiuli Wang a, Xinhui Xia a,*, \\ Jiangping $\mathrm{Tu}^{\mathrm{a}}$ \\ a State Key Laboratory of Silicon Materials, Key Laboratory of Advanced Materials and Applications for Batteries of Zhejiang Province, and School of Ma- \\ terials Science and Engineering, Zhejiang University, Hangzhou 310027, Zhejiang, China \\ b School of Engineering, Nanyang Polytechnic, 569830, Singapore \\ c Zhejiang Provincial Key Laboratory for Cutting Tools, Taizhou University, Taizhou 318000, Zhejiang, China
}

\section{A R T I C L E I N F}

\section{Article history:}

Received 11 October 2018

Accepted 23 October 2018

Published 5 July 2019

\section{Keywords:}

Oxygen evolution reaction

Nickel arrays

Electrocatalysis

Porous structure

Electrodeposition

\begin{abstract}
A B S T R A C T
It is important but challenging to design and fabricate an efficient and cost-effective electrocatalyst for the oxygen evolution reaction (OER). Herein, we report free-standing 3D nickel arrays with a cross-linked porous structure as interesting and high-performance electrocatalysts for OER via a facile one-step electrodeposition method. The 3D nickel arrays are strongly anchored on the substrate, forming self-supported electrocatalysts with reinforced structural stability and high electrical conductivity. Because of their increased active surface area, abundant channels for electron/ion transportation and enhanced electronic conductivity, the designed 3D nickel arrays exhibit superior electrocatalytic OER performance with a low overpotential (496 mV at $50 \mathrm{~mA} \mathrm{~cm}{ }^{-2}$ ) and a small Tafel slope ( $43 \mathrm{mV} \mathrm{dec}^{-1}$ ) as well as long-term stability (no decay after $24 \mathrm{~h}$ ) in alkaline solution. Our proposed rational design strategy may open up a new way to construct other advanced 3D porous materials for widespread application in electrocatalysis.
\end{abstract}

(C) 2019, Dalian Institute of Chemical Physics, Chinese Academy of Sciences. Published by Elsevier B.V. All rights reserved.

\section{Introduction}

It is always a high priority to pursue high-efficiency green energy technology in response to the drastic changes in the world's energy landscape [1-3]. Typically, electrochemical water splitting is considered to be one of the most promising strategies for environmentally friendly energy conversion [4-6]. The oxygen evolution reaction (OER), as a necessary process in water splitting, depends on continuing advances in the technology of cost-effective efficient electrocatalysts [7-11].
Currently, noble metal oxides (such as iridium/ruthenium oxides) hold the record for OER catalysts in alkaline solution [12]. However, their high cost, scarcity, and poor stability impede their widespread application $[13,14]$. Therefore, considerable efforts should be made to explore cost-effective and high-performance alternative electrocatalysts for water oxidation.

Materials based on first-row transition metals are regarded as potential candidates and have sparked worldwide interest because of their natural abundance, catalytic activity, low cost,

\footnotetext{
* Corresponding author. Tel: +86-571-87952573; Fax: +86-571-87952856; E-mail: helloxxh@zju.edu.cn

This work was supported by the National Natural Science Foundation of China (51772272, 51502263, 51728204), the Fundamental Research Funds for the Central Universities (2018QNA4011), Qianjiang Talents Plan of Zhejiang Province (QJD1602029), the Program for Innovative Research Team in University of Ministry of Education of China (IRT13037), and the Startup Foundation for Hundred-Talent Program of Zhejiang University. The authors acknowledge the SEM/TEM support from Qiaohong He, Xiaokun Ding and Fang Chen from Department of Chemistry, Zhejiang University. DOI: 10.1016/S1872-2067(18)63194-8 | http://www.sciencedirect.com/science/journal/18722067 | Chin. J. Catal., Vol. 40, No. 7, July 2019
} 
and excellent stability [15-17]. Among them, nickel-based compounds, including nickel hydroxides $[18,19]$, nickel oxides [20], nickel sulfides [21], nickel phosphides [22,23], and nickel nitrides [24,25], are representative materials that have achieved great progress as competent electrocatalysts for water oxidation reaction because of their excellent catalytic activity and remarkable electrochemical stability. In spite of their fascinating features, the OER catalytic properties of bulk Ni-based materials are still not satisfactory because of limited electroactive sites and restricted electron/ion transfer. Hence, appropriate optimization measures must be undertaken on the Ni-based materials to increase their electroactive areas and accelerate catalytic kinetics by enhancing electronic conductivity to achieve high catalytic activity. Various Ni-based electrodes have been reported as a result of developing favorable well-aligned architectures and combining them with conductive matrixes or heteroatom doping. For example, Chen and coworkers [26] fabricated a Ni/graphene electrocatalyst by combining $\mathrm{N}$-doped graphene film and nickel nanoparticles through a heterogeneous reaction process and achieved a current density of $16.3 \mathrm{~mA} \mathrm{~cm}^{-2}$ at an overpotential of $400 \mathrm{mV}$ and

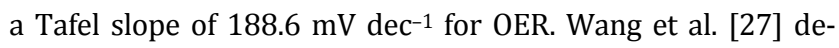
signed a $\mathrm{Ni}$ foam/porous carbon/anodized $\mathrm{Ni}$ (NF/PC/AN) electrode derived from zeolitic imidazolate framework-8 (ZIF-8), achieving an overpotential of $407 \mathrm{mV}$ at a current of 5 $\mathrm{mA} \mathrm{cm}-2$ in alkaline solution. Despite the enhanced catalytic performance for OER, the aforementioned nickel-based catalysts are still not competitive with noble metal oxides. On one hand, the performance of Ni-based catalysts without organized or tailored arrays is largely limited because the aggregation reduces active sites during the OER process. The accessible areas in the form of planar nanoarchitectures and powders for electrolyte contact are restricted, resulting in limited ion diffusion and charge transfer $[28,29]$. In contrast, binder-free 3D porous $\mathrm{Ni}$ architecture can improve electrocatalytic activity by increasing accessible areas and electrochemical active sites. Moreover, cross-linked architectures provide richer and shorter transfer channels for electron transportation and ion diffusion, leading to enhanced conductivity of catalysts. Paul et al. [30] reported hexagonal arrays of cylindrical nickel with enhanced OER performance. Their fabrication method is usually time-consuming and requires several procedures. Meanwhile, commercial nickel foam has been widely tested as a binder-free OER catalyst; however, its branch diameter and pore size are too large to provide high performance. Under such circumstances, a one-step synthesis method must be established to fabricate highly porous Ni-based arrays of electrocatalysts with high catalytic activity and good durability.

In this work, we rationally designed 3D nickel arrays with a cross-linked porous structure as efficient free-standing electrocatalysts for OER in alkaline solution by a facile one-step electrodeposition method. Owing to the enhanced electronic conductivity, increased active areas, and tight integration with the substrate, the 3D nickel arrays exhibit remarkable electrocatalytic performance for OER with a low overpotential of 496 $\mathrm{mV}$ at $50 \mathrm{~mA} \mathrm{~cm}^{-2}$ and an extreme Tafel slope of $43 \mathrm{mV} \mathrm{dec}^{-1}$ in an alkaline medium. Moreover, the 3D nickel arrays also show superior long-term stability with no decay after $24 \mathrm{~h}$. Our facile synthesis method and rational design may provide a new approach for construction of advanced and efficient non-noble-metal-based electrocatalysts for OER.

\section{Experimental}

The 3D porous nickel arrays were prepared by a facile electrodeposition method at room temperature. The synthesis procedure was performed in a typical two-electrode system. For the first step, $0.2 \mathrm{~mol} \mathrm{NH}_{4} \mathrm{Cl}$ and $0.01 \mathrm{~mol} \mathrm{NiCl}$ were dissolved in $100 \mathrm{~mL}$ deionized water at a $\mathrm{pH}$ value of 3.5 to use as the electrolyte. Then, a piece of clean nickel foil $(2 \mathrm{~cm} \times 3 \mathrm{~cm})$ was directly used as the working electrode while a platinum sheet was used as the counter electrode, where the distance was about $1 \mathrm{~cm}$. The electrodeposition was conducted at a constant current of $2 \mathrm{~A} \mathrm{~cm}^{-2}$ for $80 \mathrm{~s}$. After being rinsed with deionized water and ethanol, the as-prepared samples were dried at $60{ }^{\circ} \mathrm{C}$ overnight. A $1.0 \mathrm{~cm} \times 1.0 \mathrm{~cm}$ piece of commercial nickel foam was used for comparison; the commercial foam was ultrasonically cleaned in $1 \mathrm{~mol} \mathrm{~L}^{-1}$ hydrochloric acid, ethanol, and deionized water, successively, and then used without any further processing.

Morphologies and microstructures of the samples were obtained by field emission scanning electron microscopy (FESEM, SU8010) and high-resolution transmission electron microscopy (HRTEM, JEM 2100F). The X-ray diffraction (XRD) patterns, which were used to confirm the crystal structure, were obtained with $\mathrm{Cu} K_{\alpha}$ radiation (Rigaku D/Max-2550).

The OER performance of all samples was tested using an electrochemical workstation (CH Instrument 660D) with a typical three-electrode configuration at $25^{\circ} \mathrm{C}$. The relative tests were also supported by the NEWARE system. The test samples were used directly as the working electrodes, while a platinum foil and a standard $\mathrm{Hg} / \mathrm{HgO}$ electrode were used as the counter electrode and reference electrode, respectively. The electrolyte used in the experiments was a $1 \mathrm{~mol} \mathrm{~L}^{-1} \mathrm{KOH}$ aqueous solution. All potentials were referred to a reversible hydrogen electrode (RHE) based on the equation $E_{(\mathrm{RHE})}=E_{(\mathrm{Hg} / \mathrm{HgO})}+0.9254$. Twenty cycles of cyclic voltammetry (CV) were provided at the rate of $100 \mathrm{mV} \mathrm{s}^{-1}$ to stabilize the experimental system. Then the linear sweep voltammetry (LSV) curves were obtained at a scan rate of $5 \mathrm{mV} \mathrm{s}^{-1}$ in the potential range of 0 to $1 \mathrm{~V}$ versus the $\mathrm{Hg} / \mathrm{HgO}$ electrode. The Tafel curves were derived from the LSV curves at a scan rate of $1 \mathrm{mV} \mathrm{s}{ }^{-1}$. Electrochemical impedance spectroscopy (EIS) was conducted for each sample at correlative polarization voltage with a current density of around 10 $\mathrm{mA} \mathrm{cm}{ }^{-2}$, ranging from 0.01 to $100 \mathrm{kHz}$. Moreover, long-term chronopotentiometry measurements were continuously performed at a current density of $10 \mathrm{~mA} \mathrm{~cm}^{-2}$ for $24 \mathrm{~h}$ to estimate the stability of samples.

\section{Results and discussion}

The morphologies of all the samples were determined from SEM images. Fig. 1 illustrates the electrodeposited 3D porous nickel arrays, which are tightly and uniformly grown on the 


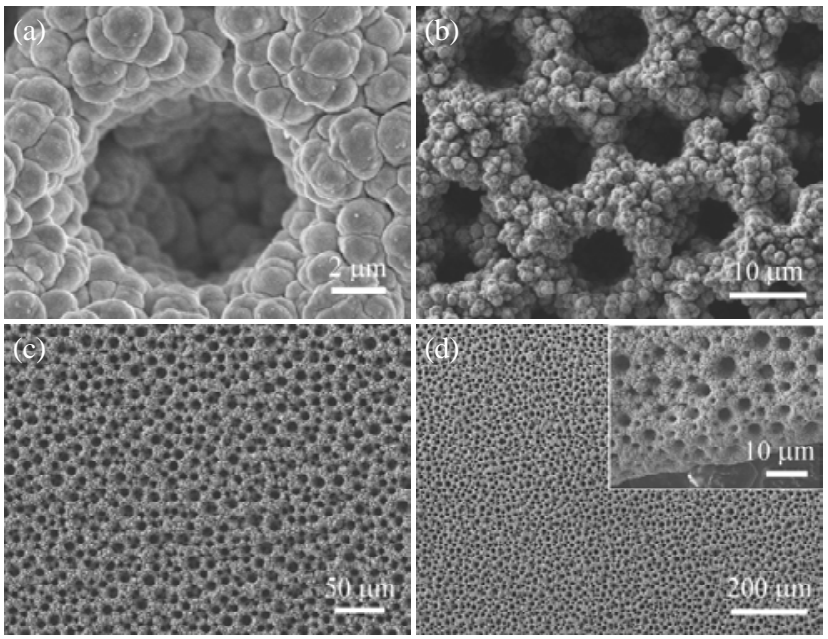

Fig. 1. SEM images of 3D nickel arrays.

nickel foil substrate. The nickel arrays display a rough surface and show a highly porous structure with cross-linked nickel branches that are composed of numerous nickel particles with diameters ranging from 0.5 to $1.5 \mu \mathrm{m}$. As clearly shown in Fig. 1 (a) and 1(b), the typical pore size of the as-prepared nickel film is in the range from 5 to $10 \mu \mathrm{m}$. The free-standing cross-linked nickel branches exhibit general widths of about 4-10 $\mu \mathrm{m}$. The specific sizes of both branches and particles in 3D nickel film can be adjusted by controlling the electrodeposition parameters including current densities and reaction time. It must also be mentioned that all the pores in the 3D nickel arrays, successfully formed both on the surface and in the inner space, are linked together and contacts extend in all directions, forming a 3D interconnected porous network (inset in Fig. $1(d))$. The accompanying hydrogen evolution that occurs during the electrodeposition process plays a critical part in the formation of the cross-linked porous nickel arrays. The bubbling hydrogen, generated from the cathodic reactions on the nickel electrode, constitutes a continuous pathway from the substrate to the interface in this process. The growth of nickel is limited by the hydrogen bubbles, because no nickel ions are available to deposit nickel in the hydrogen bubbling pathway. It should be pointed out that hydrogen not only evolves from the nickel substrate, but also arises from the deposited nickel film, leading to large pores and nanopores, respectively, through the 3D nickel film. In this synthesis procedure, hydrogen bubbles serve as dynamic templates for the construction of 3D
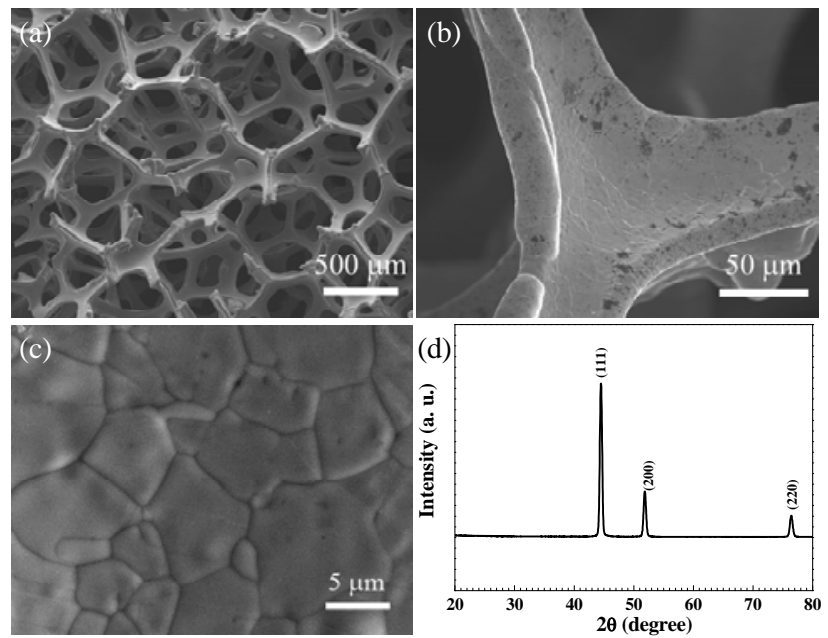

Fig. 3. $(a, b, c)$ SEM images of nickel foam. (d) XRD pattern of nickel foam.

cross-linked porous nickel arrays.

Transmission electron microscopy (TEM) examinations were conducted to obtain further insights into the detailed microstructures of the 3D porous nickel arrays. As indicated in Fig. 2(a), a nickel branch with a highly porous structure is composed of numerous nanoparticles of 200-400 nm in size, and some pores are diffusely distributed on the branch surface. The fact that the nickel phase has a well-defined polycrystalline nature is verified by the selected area electron diffraction (SAED) pattern, where the diffraction rings of (111), (200), and (220) are identified. The measured lattice spacing in Fig. 2b is about $0.20 \mathrm{~nm}$, in agreement with the (111) planes of nickel phase (JCPDS 04-0850). The crystallographic structure of 3D nickel arrays is further confirmed by XRD patterns. All diffraction peaks in Fig. 2(c) match well with the nickel phase (JCPDS 04-0850). The identified peaks at approximately $44.5^{\circ}, 51.8^{\circ}$, and $76.4^{\circ}$ are indexed to the planes of (111), (200), and (220) belonging to the nickel phase, suggesting the successful deposition of 3D nickel arrays on the nickel foil substrate.

For comparison, the morphology and structure of nickel foam were also monitored by SEM images and XRD patterns, respectively. As shown in Fig. 3(a)-(c), the commercial nickel foam exhibits a porous interconnected structure made up of solid nickel branches ranging from 50 to $80 \mu \mathrm{m}$ with a smooth surface. It can be clearly observed that the average pore size is around $200-500 \mu \mathrm{m}$, which is much larger than that of our 3D
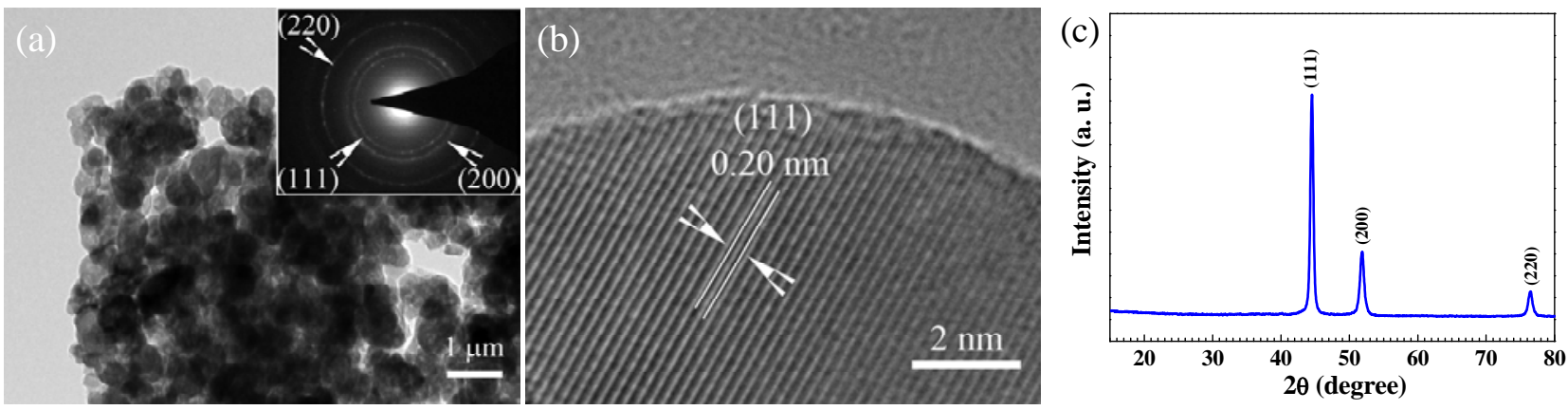

Fig. 2. (a,b) TEM and HRTEM images of 3D nickel arrays. Inset in (a) is the SAED pattern of 3D nickel arrays. (c) XRD pattern of 3D nickel arrays. 
cross-linked nickel film. The nickel particles with joint connection on the smooth surface are generally in the size range of 5-10 $\mu \mathrm{m}$, almost 10 times larger than those of our 3D nickel arrays. The XRD pattern in Fig. 3(d) confirms the crystal structure of the nickel foam. All diffraction peaks are characteristic peaks of nickel phase (JCPDS 04-0850), in agreement with the planes of (111), (200), and (220), respectively. It is worth noting that the peak width of 3D nickel film shows an evident broadening trend compared to that of nickel foam, which is in accordance with the reduced nanoparticle size and the successful micro-nano construction of the 3D porous nickel film. Above all, these results demonstrate conclusively that 3D cross-linked porous nickel arrays have been successfully prepared by a facile electrodeposition method. Moreover, our electrode rational design can be readily extended to construct other 3D metal nanostructures for a wide range of applications in energy conversion and storage.

The electrochemical properties of 3D porous nickel arrays (denoted as 3D Ni) as electrocatalysts for OER were further investigated in a typical three-electrode system. Nickel foam (denoted as NF) was also investigated as comparison. The catalytic performance of 3D Ni and NF for OER was first investigated via LSV as shown in Fig. 4(a). It is not accurate to use an overpotential at the current density of $10 \mathrm{~mA} \mathrm{~cm}^{-2}$ for $3 \mathrm{D} \mathrm{Ni}$ owing to the existence of the huge redox peak. The 3D Ni arrays exhibit the best OER performance with the extremely low overpotential of $496 \mathrm{mV}$ (vs. RHE) at $50 \mathrm{~mA} \mathrm{~cm}^{-2}$, which is superior to the NF (597 mV vs. RHE at $10 \mathrm{~mA} \mathrm{~cm}^{-2}$ ). Notably, the 3D Ni shows higher current densities than the NF at the same overpotential. This indicates that the cross-linked porous nanostructures are more favorable for the catalytic improvement of OER, which is further proven by Tafel plots (Fig. 4(b)). The Tafel slopes are determined to assess the OER kinetics and can be derived from the LSV curves according to the equation $\eta$ $=a+b \log j$ (where $\eta, j$, and $b$ represent the overpotential, current density, and Tafel slope, respectively). The Tafel equation is applicable to the region where the values of polarization are high. At low values of polarization, the dependence of current on polarization is usually linear, rather than logarithmic. As a result, the current range between 1 and $10 \mathrm{~mA} \mathrm{~cm}-2$ is collected. A smaller Tafel slope indicates faster kinetics of the OER, meaning a more rapid increase of current density with the same enhancement of overpotentials [31,32]. The Tafel slope of 3D Ni is approximately $43 \mathrm{mV} \mathrm{dec}-1$, which is much lower than that of NF (195 mV $\mathrm{dec}^{-1}$ ), demonstrating its faster OER process.

The electrochemically active surface areas (ECSA) for 3D Ni and $\mathrm{NF}$ are estimated from the electrochemical double-layer capacitances ( $\left.C_{\mathrm{dl}}\right)$ of two samples to explain the enhancement of catalytic performance for OER [12,33]. Plots in Fig. 4(c) are obtained by measuring the non-Faradaic capacitive current in agreement with double-layer charging from the cycling voltammograms (CVs) at different scan rates (Fig. 5). The ECSA is linearly proportional to the $C_{\mathrm{dl}}$ values and is equal to half of the slope value. It is evident that the highest capacitance $(15.5 \mathrm{mF}$ $\mathrm{cm}^{-2}$ ) is achieved by the 3D Ni electrode, and that this is much larger than that of the $\mathrm{NF}\left(1.8 \mathrm{mF} \mathrm{cm}^{-2}\right)$, demonstrating the increased active areas and hence better electrocatalytic properties of 3D Ni for OER. Moreover, the electrochemical behavior of samples in the OER process is revealed by EIS at an overpotential of $195 \mathrm{mV}$. As presented in Fig. 4(d), the intercept of the $X$-axis for 3D Ni is smaller than for NF in the high-frequency region, implying that $3 \mathrm{D}$ Ni possesses smaller bulk resistance, faster charge transfer, and faster catalytic reaction kinetics. The rational design of the cross-linked porous structure provides considerable improvement of the electrocatalytic performance for OER: (1) Direct growth of 3D Ni arrays on the nickel foil substrate ensures high electrical conductivity and exposes
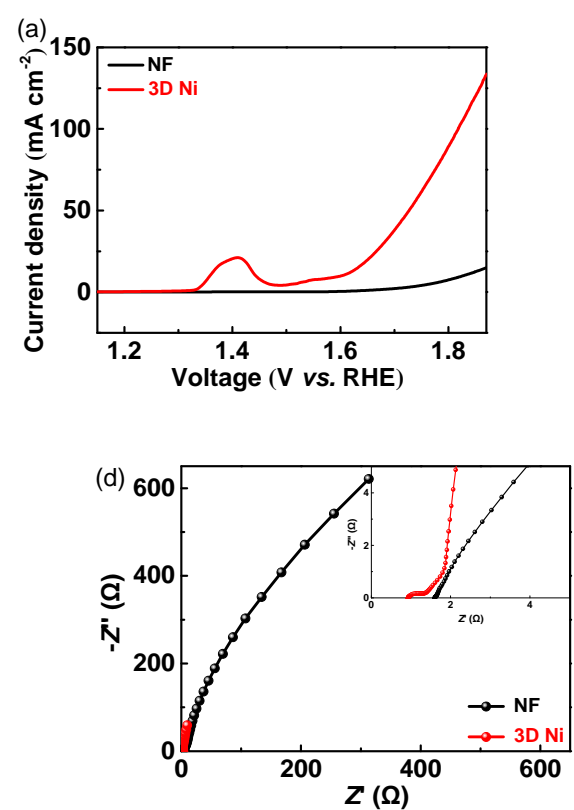

(b)

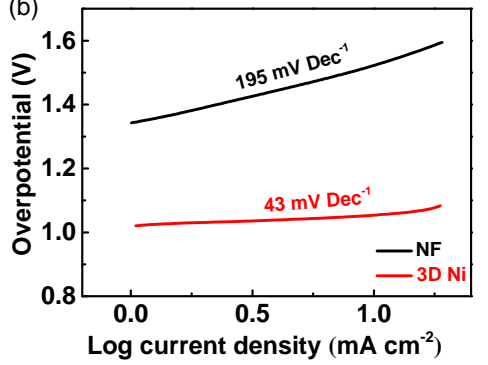

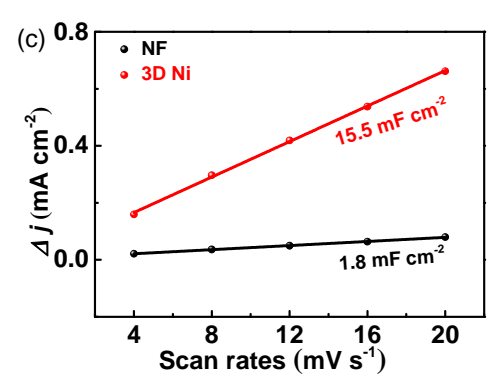

(e)

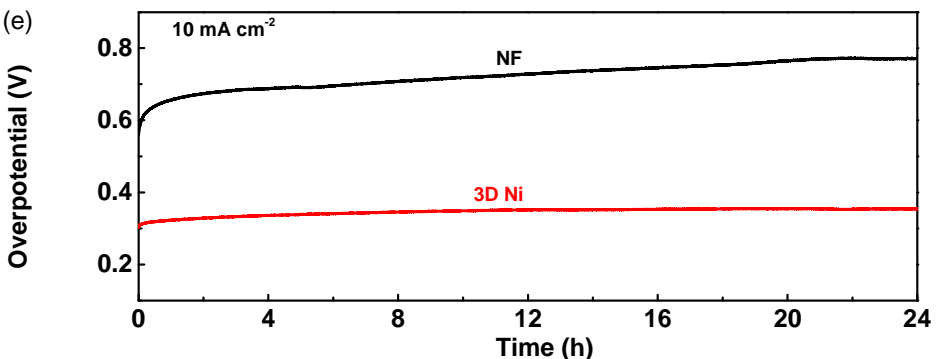

Fig. 4. OER performance of the Ni foam and 3D nickel arrays electrodes. (a) LSV curves at 5 mV s ${ }^{-1}$; (b) Tafel plots; (c) Nyquist plots; (d) Ratio of current density with various scan rates; (e) Electrochemical stability. 
(a)

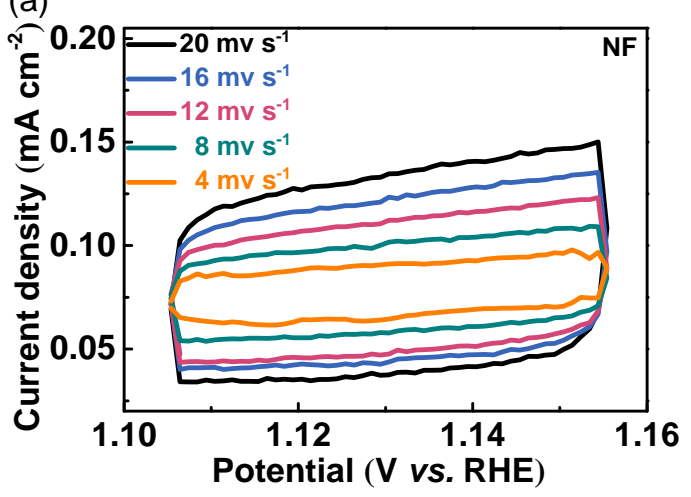

(b)

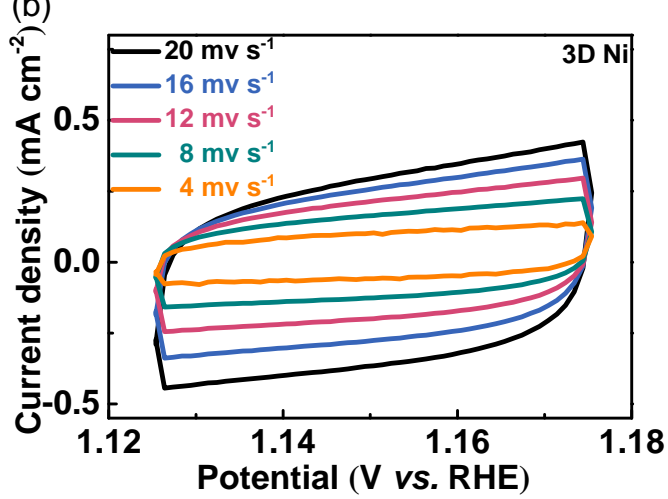

Fig. 5. CV curves of different electrodes in double layer region at scan rates of 4-20 mV s $\mathrm{m}^{-1}$. (a) Ni foam; (b) 3D nickel arrays.

more reaction sites while avoiding the use of polymer binders [34,35]; (2) the cross-linked 3D nickel arrays with their highly porous structure increase active areas and promote sufficient contact with the electrolyte, dramatically accelerating ion diffusion [36,37]. The open porous framework of 3D Ni arrays promotes the penetration of electrolyte and the release of oxygen bubbles. Meanwhile, the cross-linked skeletons can serve as channels to achieve a short path-length for electron transportation and ion diffusion, leading to reduced bulk resistance and faster catalytic kinetics [38-40]. In addition, a long-time chronopotentiometry measurement was carried out at $10 \mathrm{~mA}$ $\mathrm{cm}^{-2}$ for $24 \mathrm{~h}$ to evaluate the stability of the samples. The curve of 3D Ni remains flat while the curve of NF presents an obvious upward trend, demonstrating that the 3D Ni possesses lower overpotential and better durability in the long-term OER process. Above all, we can confidently conclude that the 3D Ni is an efficient electrocatalyst with superior catalytic performance for OER and excellent stability in alkaline solution, which opens up the potential to design advanced catalysts based on the cross-linked porous architecture for widespread applications in energy storage and conversion.

\section{Conclusions}

We have demonstrated that the 3D nickel arrays produced by a versatile one-step electrodeposition method are robust, high-efficiency electrocatalysts. The rational design for interconnected highly porous construction allows larger active surface area, richer transport channels for electron/ion transfer, and improved electron conductivity. The nickel arrays are firmly integrated with the Ni substrate, ensuring good mechanical stability. Moreover, the proposed fabrication approach is facile and applicable to various conductive supports and porous morphology. Thus, the as-obtained 3D nickel arrays achieve superior electrochemical performance with a lower overpotential of $496 \mathrm{mV}$ at $50 \mathrm{~mA} \mathrm{~cm}^{-2}$, a smaller Tafel slope of $43 \mathrm{mV} \mathrm{dec}^{-1}$, and long-time durability for $24 \mathrm{~h}$. Our work has demonstrated a promising approach for design of advanced transition metal electrocatalysts and may inspire construction of various other porous materials applicable in electrocatalysis.

\section{References}

[1] W. Xu, H. Wang, Chin. J. Catal., 2017, 38, 991-1005.

[2] Y. Jiao, Y. Zheng, M. Jaroniec, S. Z. Qiao, Chem. Soc. Rev., 2015, 44, 2060-2086.

[3] X. He, F. Yin, H. Wang, B. Chen, G. Li, Chin. J. Catal., 2018, 39, 207-227.

[4] S. Deng, F. Yang, Q. Zhang, Y. Zhong, Y. Zeng, S. Lin, X. Wang, X. Lu, C. Z. Wang, L. Gu, X. Xia, J. Tu, Adv. Mater. , 2018, 30, 1802223.

[5] J. Li, G. Du, X. Cheng, P. Feng, X. Luo, Chin. J. Catal., 2018, 39, 982-987.

[6] R. Souleymen, Z. Wang, C. Qiao, M. Naveed, C. Cao, J. Mater. Chem. A, 2018, 6, 7592-7607.

[7] S. Deng, Y. Zhong, Y. Zeng, Y. Wang, Z. Yao, F. Yang, S. Lin, X. Wang, X. Lu, X. Xia, J. Tu, Adv. Mater., 2017, 29, 1700748.

[8] S. Deng, Y. Zhong, Y. Zeng, Y. Wang, X. Wang, X. Lu, X. Xia, J. Tu, Adv. Sci., 2018, 5, 1700772.

[9] S. Deng, S. Shen, Y. Zhong, K. Zhang, J. Wu, X. Wang, X. Xia, J. Tu, J. Energy Chem., 2017, 26, 1203-1209.

[10] A. Swesi, J. Masud, M. Nath, Energy Environ. Sci., 2016, 9, 1771-1782.

[11] X. Zhao, W. Zhang, R. Cao, J. Energy Chem., 2017, 26, 1210-1216.

[12] C. C. L. McCrory, S. Jung, J. C. Peters, T. F. Jaramillo, J. Am. Chem. Soc., 2013, 135, 16977-16987.

[13] J. T. Zhang, Z. H. Zhao, Z. H. Xia, L. M. Dai, Nat. Nanotechnol., 2015, 10, 444-452.

[14] B. Q. Li, C. Tang, H. F. Wang, X. L. Zhu, Q. Zhang, Sci. Adv., 2016, 2, e1600495.

[15] L. Trotochaud, S. L. Young, J. K. Ranney, S. W. Boettcher, J. Am. Chem. Soc., 2014, 136, 6744-6753.

[16] J. Jiang, F. Sun, S. Zhou, W. Hu, H. Zhang, J. Dong, Z. Jiang, J. Zhao, J. Li, W. Yan, M. Wang, Nat. Commun., 2018, 9, 2885.

[17] L. Peng, S. S. A. Shah, Z. Wei, Chin. J. Catal., 2018, 39, 1575-1593.

[18] M. Gao, W. Sheng, Z. Zhuang, Q. Fang, S. Gu, J. Jiang, Y. Yan, J. Am. Chem. Soc., 2014, 136, 7077-7084.

[19] R. Subbaraman, D. Tripkovic, K. C. Chang, D. Strmcnik, A. P. Paulikas, P. Hirunsit, M. Chan, J. Greeley, V. Stamenkovic, N. M. Markovic, Nat. Mater., 2012, 11, 550-557.

[20] I. J. Godwin, M. E. G. Lyons, Electrochem. Commun., 2013, 32, 39-42.

[21] W. Zhou, X. J. Wu, X. Cao, X. Huang, C. Tan, J. Tian, H. Liu, J. Wang, H. Zhang, Energy Environ. Sci., 2013, 6, 2921-2924.

[22] X. Yu, Y. Feng, B. Guan, X. W. Lou, U. Paik, Energy Environ. Sci., 


\title{
Graphical Abstract
}

Chin. J. Catal., 2019, 40: 1063-1069 doi: 10.1016/S1872-2067(18)63194-8

Rational construction of cross-linked porous nickel arrays for efficient oxygen evolution reaction

Kaili Zhang, Shengjue Deng, Yu Zhong, Yadong Wang, Jianbo Wu, Xiuli Wang, Xinhui Xia *, Jiangping Tu

Zhejiang University, China; Nanyang Polytechnic. Singapore;

Taizhou University, China

Free-standing 3D nickel arrays with cross-linked highly porous structure are prepared by a versatile one-step electrodeposition method and show superior electrocatalytic performance and remarkable long-term durability.

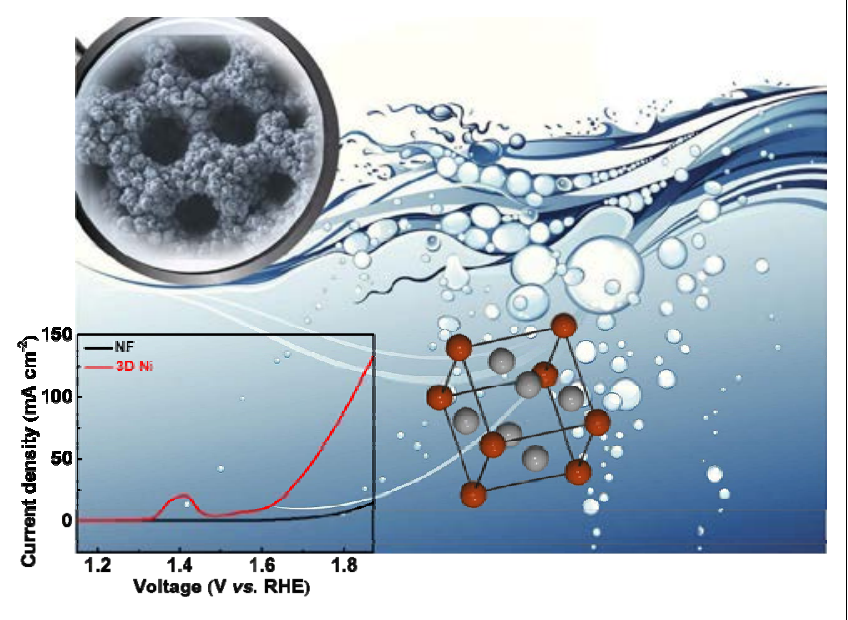

2016, 9, 1246-1250.

[23] B. You, N. Jiang, M. Sheng, M. W. Bhushan, Y. Sun, ACS Catal., 2016, $6,714-721$.

[24] M. Xu, L. Han, Y. J. Han, Y. Yu, J. F. Zhai, S. J. Dong, J. Mater. Chem. A, 2015, 3, 21471-21477.

[25] M. Shalom, D. Ressnig, X. Yang, G. Clavel, T. P. Fellinger, M. Antonietti, J. Mater. Chem. A, 2015, 3, 8171-8177.

[26] S. Chen, J. Duan, J. Ran, M. Jaroniec, S. Z. Qiao, Energy Environ. Sci., 2013, 6, 3693-3699.

[27] J. Wang, H. X. Zhong, Y. L. Qin, X. B. Zhang, Angew. Chem. Int. Ed., 2013, 52, 5248-5253.

[28] G. Cai, W. Zhang, L. Jiao, S. H. Yu, H. L. Jiang, Chem, 2017, 2, 791-802.

[29] S. Chen, J. Duan, M. Jaroniec, S. Z. Qiao, Adv. Mater., 2014, 26, 2925-2930.

[30] M. T. Y. Paul, B. B. Yee, D. R. Bruce, B. D. Gates, ACS Appl. Mater. Interfaces, 2017, 9, 7036-7043.

[31] X. Li, Y. Fang, X. Lin, M. Tian, X. An, Y. Fu, R. Li, J. Jin, J. Ma, J. Mater. Chem. A, 2015, 3, 17392-17402.
[32] G. Fu, X. Yan, Y. Chen, L. Xu, D. Sun, J. M. Lee, Y. Tang, Adv. Mater, 2018, 30, 1704609.

[33] Y. Zhang, B. Ouyang, J. Xu, S. Chen, R. S. Rawat, H. J. Fan, Adv. Energy Mater., 2016, 6, 1600221.

[34] Y. Zhong, X. Xia, S. Deng, D. Xie, S. Shen, K. Zhang, W. Guo, X. Wang, J. Tu, Adv. Mater., https://doi.org/10.1002/adma.201805165.

[35] L. Zhang, X. Xia, Y. Zhong, D. Xie, S. Liu, X. Wang, J. Tu, Adv. Mater., 2018, https://doi.org/10.1002/adma.201804011.

[36] X. Xia, S. Deng, D. Xie, Y. Wang, S. Feng, J. Wu, J. Tu, J. Mater. Chem. A, 2018, 6, 15546-15552.

[37] Q. Xiong, H. Chi, J. Zhang, J. Tu, J. Alloys Compd., 2016, 688, 729-735.

[38] Q. Xiong, C. Zheng, H. Chi, J. Zhang, Z. Ji, Nanotechnology, 2017, 28, 055405.

[39] Q. Q. Xiong, J. J. Lou, X. J. Teng, X. X. Lu, S. Y. Liu, H. Z. Chi, Z. G. Ji, J. Alloys Compd., 2018, 743, 377-382.

[40] Z. Yao, X. Xia, D. Xie, Y. Wang, C. Zhou, S. Liu, S. Deng, X. Wang, J. Tu, Adv. Funct. Mater., 2018, 28, 1802756.

\section{用于高效析氧反应的交联多孔镍阵列的合理构建}

\author{
张凯丽 ${ }^{\mathrm{a}}$, 邓盛玨 ${ }^{\mathrm{a}}$, 钟 宇 ${ }^{\mathrm{a}}$, 王亚东 ${ }^{\mathrm{b}}$, 吴建波 ${ }^{\mathrm{c}}$, 王秀丽 ${ }^{\mathrm{a}}$, 夏新辉 ${ }^{\mathrm{a}}{ }^{*}$, 涂江平 $^{\mathrm{a}}$ \\ a浙江大学材料科学与工程学院硅材料国家重点实验室, \\ 浙江省电池新材料与应用技术研究重点实验室, 浙江杭州310027, 中国

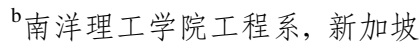 \\ ‘台州学院浙江省工量刀具检测与深加工技术研究重点实验室, 浙江台州318000, 中国
}

摘要: 为应对世界能源格局的巨大变化, 追求高效绿色能源技术研究始终是一个热点. 通常, 电化学水分解被认为是最有 潜力的环境友好型能量转换策略之一. 氧气释放反应(OER)作为水分解的必要过程依赖于低成本高效电催化剂的发展. 目 前, 贵金属氧化物(如氧化铱/氧化钓) 被认为是碱性溶液中最高效的OER催化剂. 然而, 高成本、稀缺性和不稳定性阻碍了它 们的广泛应用. 因此, 探索成本低廉且高效的OER电催化剂成为现今工作的重点. 以过渡金属为基础的催化剂因其天然丰 度、较高的催化活性、低廉的成本和较好的循环稳定性受到人们的青崃. 其中, 包括氢氧化镍、氧化镍、硫化镍、磷化镍 等在内的镍基化合物是最有代表性的研究对象. 到目前为止, 已有很多工作对镍基材料进行优化来增强其电子导电性和 电化学活性面积, 从而大大提高了 OER催化性能. 但是, 这些非阵列的镍基材料由于物质团聚导致反应活性位点被覆盖, 
同时平面或者粉末状的结构使得材料表面与电解液的接触面积有限, 因而催化性能受到限制. 相比之下, 无粘合剂的3D多 孔镍结构通过增加可接触面积和电化学活性位点来改善电催化活性, 交联结构也为电子传输和离子扩散提供了更丰富和 更短的传输通道, 从而提高了催化剂的导电性, 有利于电催化性能的提高.

本文通过简便的一步电沉积方法合理地设计了具有交联多孔结构的3D镍阵列作为碱性溶液中自支撑的高效OER电催 化剂. SEM图清晰地展示了3D多孔镍阵列的形貌特征. 3D镍与基底结合紧密且均匀有序地生长, 表现出高度交联分支的 多孔结构, 样品由许多直径为 $0.5-1.5 \mu \mathrm{m}$ 的镍颗粒构成, 阵列的孔洞直径为 $5-10 \mu \mathrm{m}$. 对 $3 \mathrm{D}$ 多孔镍阵列的形成机理进行了探 讨. 利用TEM和XRD对样品进行了微观结构和物相的进一步表征, 发现镍分支由200-400 nm的纳米颗粒组成. 通过晶面 间距、电子选区衍射和XRD图谱确定合成了镍的纯相, 并与泡沫镍的形貌和物相进行了对比. 样品的电催化性能测试表明, 与泡沫镍相比, 3D多孔镍表现出优越的OER电催化性能, 具有较低的过电位 $\left(50 \mathrm{~mA} \mathrm{~cm}{ }^{-2}\right.$ 时为 $\left.496 \mathrm{mV}\right)$ 、较小的Tafel斜率(43 $\mathrm{mV} \mathrm{dec}{ }^{-1}$ )、较小的电阻、较大的电化学活性面积以及碱性溶液中的长期稳定性(24小时后无衰变). 同时, 我们在对3D多孔 镍催化性能提高的原因进行了分析. 本文提出的合理设计策略可为其他先进3D多孔材料的构建以及电催化剂的改进提供 一个新思路.

关键词: 氧气释放反应; 镍阵列; 电催化; 多孔结构; 电沉积

收稿日期: 2018-10-11. 接受日期: 2018-10-23. 出版日期: 2019-07-05.

*通讯联系人. 电话: (0571)87952573; 传真: (0571)87952856; 电子信箱: helloxxh@zju.edu.cn

基金来源：国家自然科学基金(51772272，51502263，51728204); 中央高校基本科研业务费专项资金(2018QNA4011); 浙江省“钱 江人才计划”(QJD1602029); 教育部“创新团队发展计划”(IRT13037); 浙江大学百人计划启动基金.

本文的电子版全文由Elsevier出版社在ScienceDirect上出版(http://www.sciencedirect.com/science/journal/18722067). 